\title{
Purification optimization for a recombinant single-chain variable fragment against type 1 insulin-like growth factor receptor (IGF-1R) by using design of experiment (DoE)
}

\author{
Yong-Hong Song $^{\text {a b, }}{ }^{\Delta}$, Xue-Wen Sun ${ }^{\text {b, } \Delta}$, Bo Jiang ${ }^{\text {c }}$, Ji-En Liu ${ }^{\text {d }}$, Xian-Hui Su ${ }^{\text {a,b,* }}$ \\ ${ }^{\mathrm{a}}$ The Affiliated Hospital of Hebei University of Engineering, Handan, China \\ ${ }^{\mathrm{b}}$ Medical College, Hebei University of Engineering, Handan, China

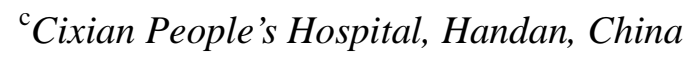 \\ ${ }^{\mathrm{d}}$ Handan Central Hospital, Handan, China
}

${ }^{\triangle}$ Yong-Hong Song and Xue-Wen Sun contributed equally to this paper.

${ }^{*}$ Corresponding author: Xian_Hui Su, ${ }^{\mathrm{a}}$ The Affiliated Hospital of Hebei University of Engineering, Handan, China, ${ }^{\mathrm{b}}$ Medical College, Hebei University of Engineering,

Handan, China, Handan 056002, China. Tel: +86-310-2923059, Fax:

+86-310-2923059, E-mail: Xianhui_Su@yeah.net 


\section{Abstract}

Design of experiment (DoE) is a statistics-based technique for experimental design that could overcome the shortcomings of traditional one-factor-at-a-time (OFAT) approach for protein purification optimization. In this study, a DoE approach was applied for optimizing purification of a recombinant single-chain variable fragment (scFv) against type 1 insulin-like growth factor receptor (IGF-1R) expressed in E. coli. In first capture step using Capto L, a 2-level fractional factorial analysis and successively a central composite circumscribed (CCC) design were used to identify the optimal elution conditions. Two main effects, $\mathrm{pH}$ and trehalose, were identified, and high recovery (above 95\%) and low aggregates ratio (below 10\%) were achieved at the $\mathrm{pH}$ range from 2.9 to 3.0 with $32 \%-35 \%(\mathrm{w} / \mathrm{v})$ trehalose added. In the second step using cation exchange chromatography, an initial screening of media and elution $\mathrm{pH}$ and a following $\mathrm{CCC}$ design were performed, whereby the optimal selectivity of the $\mathrm{scFv}$ was obtained on Capto $\mathrm{S}$ at $\mathrm{pH}$ near 6.0, and the optimal conditions for fulfilling high $\mathrm{DBC}$ and purity were identified as $\mathrm{pH}$ range of 5.9-6.1 and loading conductivity range of $5-12.5 \mathrm{mS} / \mathrm{cm}$. Upon a further gel filtration, the final purified $\mathrm{scFv}$ with a purity of $98 \%$ was obtained. Finally, the optimized conditions were verified by a 20-fold scale-up experiment. The purities and yields of intermediate and final products all fell within the regions predicted by DoE approach, suggesting the robustness of the optimized conditions. We proposed that the DoE approach described here is also applicable in production of other recombinant antibody constructs. Keywords: IGF-IR; ScFv; DoE; Design of experiment; Fractional factorial analysis; Central composite circumscribed design. 


\section{Introduction}

Human insulin-like growth factor 1 receptor (IGF-1R) is a transmembrane receptor of insulin-like growth factor 1 (IGF-1) and IGF-2 [1]. It has been widely reported that IGF-1R is implicated in several cancers [2-3], suggesting a promising target for a wide range of cancers. The monoclonal antibodies against IGF-IR have been demonstrated to inhibit cancer cell growth [4].

Single-chain variable fragment $(\mathrm{scFv})$ is a fusion protein of the variable domains of heavy chain and light chain of full-length antibody [5]. $\mathrm{ScFv}$ has better permeability to target site in tissues than full-length antibody because of its small size, and has been widely developed for therapeutic or diagnostic interest [5-6]. In our previous work, we have expressed a soluble bioactive scFv against IGF-IR in E. coli periplastic space [7]. In this study, we aimed to purify the $s c F v$ for further development.

Protein purification is a multifactorial exercise, as many factors such as sample composition, purification technique, chromatography media, binding, wash, and elution conditions all might play a role. In a traditional way for optimization of protein purification, one-factor-at-a-time (OFAT) approach is employed. Such approach involves varying one variable at a time, while keeping other variables constant. Thus it requires a number of experiments to be carried out, making this approach time-consuming and labor intensive. Moreover, it often fails to predict the genuine optimal conditions because the setup just covers a limited part of the experiment space and does not include the combined effects of all the variables 
involved. These shortcomings can be overcome by design of experiment (DoE), which is a statistics-based technique for designing experiments and analyzing the information obtained [8]. The advantage of this technique is that a wide range of experimental parameters or variables could be varied systematically and simultaneously, enabling obtainment of sufficient information using minimum number of experiments. Furthermore, DoE allows detection of interactive effects of different factors, thus ensuring the reliability and robustness of the optimal conditions obtained. In recent years, a number of study cases have proved the high efficiency of DoE approach on protein purification optimization [8-10].

In this study, we described the optimization of purification process for a soluble scFv against IGF-IR using DoE approach to obtain the final product with high purity and recovery.

\section{Materials and Methods}

Chemicals, chromatography media and equipment

IPTG, arabinose, urea, PEG (MW 2,000), dextran, arginine, trehalose, sodium phosphate (monobasic and dibasic) and other commonly used chemicals were all purchased from Sigma-Aldrich (Shanghai, China). The chromatography media and prepacked columns for protein purification were all purchased from GE Healthcare (Shanghai, China). An ÄKTA Purifier 100 (GE Healthcare) was used for the purification process development.

Expression of the recombinant $s c F v$ against IGF-IR

The plasmid construction and expression of the recombinant $\mathrm{scFv}$ against IGF-IR 
was conducted as described in our previous report [11] with an exception that the sequence encoding $\mathrm{C}$-terminus $6 \times$ His tag was removed here. Briefly, the variable region of heavy chain $(\mathrm{VH})$ and variable region of light chain (VL) derived from a monoclonal antibody (CP 751871) against IGF-1R [7] were connected into a scFv via a linker peptide $\left(\mathrm{Gly}_{4} \mathrm{Ser}\right)_{3}$. The cDNA encoding such $\mathrm{scFv}$ construct was codon optimized, synthesized, cloned into the Nco I-EcoR I site of pET-26b(+) (Novagen) and designated as pET_scFv. For soluble expression of the scFv, the pET_scFv and a vector $\mathrm{pDsbA/C}$ carrying two chaperone-encoding sequences (DsbA and DsbC) were co-transformed into E. coli BL21 (DE3) (more details can be seen in [11]). The positive transformant was inoculated into $2 \times$ YT media and grown at $30 \square$ until the $\mathrm{OD}_{600}$ reached $0.5-0.8$ and then induced with $0.2 \%$ arabinose $1 \mathrm{~h}$ prior to the addition of $0.2 \mathrm{mM}$ IPTG, following which the $\mathrm{scFv}$ production was typically allowed to continue for 4-10 h. Forty grams of wet weight cell pellets were suspended in $600 \mathrm{~mL}$ lysis buffer (20 mM sodium phosphate, $150 \mathrm{mM} \mathrm{NaCl,} 5$ mM EDTA, pH 7.5), broken by a high pressure homogenizer (ATS, Canada) and then centrifuged. The supernatant of the cell lysate was collected and filtered by $0.22 \mu \mathrm{m}$ membrane for further purification.

Purification optimization by using DoE in small scale

A three-step process consisting of a capture step by Capto $\mathrm{L}^{\mathrm{TM}}$ affinity chromatography and two polishing steps with cation exchange and gel filtration respectively was used to purify the target $\mathrm{scFv}$. The DoE approach was applied in the first two steps. In general, an initial screening of wide range of parameters or factors, 
including chromatography media, dynamic binding capacities (DBC), and wash and elution conditions, was carried out to identify the ones that have significant effects on the response, and to determine which factors need to be further optimized. Then an optimization was performed for determining optimal factor settings.

For the capture step, Capto $\mathrm{L}^{\mathrm{TM}}$ medium was chosen as it possesses specific affinity to antibody or antibody fragment with kappa domain. The DBC and elution $\mathrm{pH}$ range were firstly determined using a $1-\mathrm{mL}$ prepacked column. The $\mathrm{DBC}$ at $10 \%$ breakthrough (QB10\%) was determined by frontal analysis using the following parameters (column: 1-mL prepacked Capto $\mathrm{L}^{\mathrm{TM}}$; residence time: 4 min; equilibration buffer: $20 \mathrm{mM}$ sodium phosphate, $150 \mathrm{mM} \mathrm{NaCl}, \mathrm{pH}$ 7.5; sample: purified scFv 2.5 $\mathrm{mg} / \mathrm{mL}$ in equilibration buffer), and a $70 \%$ of the $\mathrm{DBC}$ at QB\%10 was selected as loading condition in following experiments. Prior to a $\mathrm{pH}$ linear gradient elution from 6.0 to 2.5 performed to identify the appropriate elution $\mathrm{pH}$, a washing step with five column-volumes (CV) of equilibration buffer was operated. For further optimizing the elution conditions, a 2-level fractional factorial analysis with resolution $\square$ was designed as shown in Table 1, seven factors were included as variables, and aggregates and recovery of the target protein were selected as responses. Two main factors, $\mathrm{pH}$ and trehalose, impacting the two responses were identified from the fractional factorial analysis, and then subjected to a central composite circumstances (CCC) analysis (see details in Table 2) to obtain the optimal experiment space of elution step. The Capto $\mathrm{L}^{\mathrm{TM}}$ elution pool was immediately diluted by $1 \mathrm{M}$ Tris- $\mathrm{Cl}$ ( $\mathrm{pH}$ 8.0) to neutralize the $\mathrm{pH}$ for temporary storage or further purification. 
For the second purification step, a comparison of two cationic exchange media, Capto S and SP Sepharose ${ }^{\circledR}$ Fast Flow, mainly on the selectivity and recovery at three different pHs, was conducted in an initial screening phase with following loading parameters (column: $1 \mathrm{~mL}$ HiTrap; residence time: 2 min; equilibration buffer: 20 $\mathrm{mM}$ sodium citrate at $\mathrm{pH} 5.0$ and 6.0 , and $20 \mathrm{mM}$ sodium phosphate at $\mathrm{pH} 7.0$; sample: the Capto L eluent adjusted to $2 \mathrm{mg} / \mathrm{mL}$ in equilibration buffer). Accordingly, six runs, using two media and each at three pHs, were carried out. In each run, equal amount $(10 \mathrm{mg})$ sample diluted in equilibration buffer was loaded, and a $5 \mathrm{CV}$ washing with equilibration buffer and a $15 \mathrm{CV}$ length of linear salt gradient elution from 0 to $1 \mathrm{M} \mathrm{NaCl}$ were followed. In addition, the $\mathrm{pH}$ values of all buffers used in each individual run were kept consistent. Based on the comparison, Capto $\mathrm{S}$ at $\mathrm{pH} 6.0$ showed the best selectivity, thus it was selected in this step. Then, a central composite circumscribed (CCC) analysis (see details in Table 3), in which $\mathrm{pH}$ and conductivity were selected as variables and $\mathrm{DBC}$ as response, was used for loading conditions optimization by using a Tricorn ${ }^{\mathrm{TM}} 5 / 100$ column. Next, the purities of the target scFvs at all set points were also tested when $70 \%$ of the DBC was set as loading condition. The conditions where both criteria of purity and DBC were fulfilled were identified as operational space in this step.

For the final step, a gel filtration with Superdex 75 10/300 GL column (GE Healthcare) was used for further polishing. The running buffer is PBS and the loading volume is less than $5 \% \mathrm{CV}$ of the column.

The experimental design and results analysis were performed by using the 
software Minitab 16 (Minitab Inc., USA).

Verification of the optimized conditions in scale-up experiment

To verify the optimized conditions, the supernatant of cell lysates from $8 \mathrm{~L}$ cultures (250 mg target protein included) was loaded as starting sample. The column size in each purification step was accordingly scaled up to fit the change in loading amount, while other conditions remained the same as that optimized above of which the center point value of each optimal space was adopted. A Hiscale ${ }^{\mathrm{TM}} 16 / 40$ column (16 mm diameter) (GE Healthcare) with Capto ${ }^{\mathrm{TM}} \mathrm{L}$ volume of $20 \mathrm{~mL}$ and a Tricorn 10/100 column with Capto ${ }^{\mathrm{TM}} \mathrm{S}$ volume of $4 \mathrm{~mL}$ were employed in the capture step and the cationic exchange step respectively. A Superdex 75 column of $800 \mathrm{~mm}$ in bed height and $16 \mathrm{~mm}$ in inner diameter was used in final step. Eluted peaks from all steps were collected and subjected to recovery and purity analysis.

\section{Analytical methods}

Protein quantification was performed by using Quant-iT Protein Assay Kit (Life Technologies). A Superdex $75^{\mathrm{TM}}$ 10/300 GL column (GE Healthcare) was used for determining aggregates and aggregate clearance. Briefly, $100 \mu l$ samples were loaded and run with PBS buffer at $0.5 \mathrm{~mL} / \mathrm{min}$, and UV absorbance at $280 \mathrm{~nm}$ was monitored. The percentage of aggregates was calculated as the aggregates peak area relative to the sum of the scFv peak area. Purity of the target protein was determined by using both SDS-PAGE analysis and SEC-HPLC analysis. The SEC-HPLC was performed on an Agilent 1200 HPLC system using BIOSep-SEC-S2000 column $(300 \times 7.8$ mm, Phenomenex), and PBS buffer was used as mobile phase at $0.5 \mathrm{~mL} / \mathrm{min}$. 


\section{Results}

Soluble expression of the scFv against IGF-IR in E. coli

In our previous work, we have achieved soluble expression of a bioactive scFv specific against IFG-IR in periplasmic space of E. coli [7]. In this study, the same recombinant $\mathrm{scFv}$ was expressed as described before except that the $6 \times$ His tag was removed. A comparable yield $(2.5 \mathrm{mg} / \mathrm{g}$ of wet weight cells in shaking flask) of soluble target $\mathrm{scFv}$ to that in previous study was obtained.

Experimental design in the capture step using Capto L affinity chromatography

In the capture step, a HiTrap ${ }^{\mathrm{TM}}$ Capto $\mathrm{L}^{\mathrm{TM}}$ prepacked $1-\mathrm{ml}$ column was chosen because of its specific affinity to kappa light chain which was included in the target $\mathrm{scFv}$. Before the application of DoE, the DBC and elution $\mathrm{pH}$ range were firstly determined to define the initial loading and elution conditions. As the result, the DBC was $18 \mathrm{mg} / \mathrm{mL}$ with a residence time of $4 \mathrm{~min}$, and the $\mathrm{pH}$ corresponding to the elution peak of the $\mathrm{scFv}$ was determined to be 3.25 based on a decreased $\mathrm{pH}$ linear gradient elution from 6.0 to 2.5 . During this step, more than $30 \%$ of target protein was eluted as soluble aggregates, mainly in dimer form (see Fig.1, lane 2), although the purity of the target protein was above $90 \%$ if the aggregates were included. This suggested that the $\mathrm{scFv}$ might be aggregation-prone in acidic $\mathrm{pH}$, thus preventing aggregation was a major task in this step. A following 2-level fractional factorial analysis to identify the main effects that inhibit aggregation during elution was conducted, where aggregates and recovery were defined as responses, and elution $\mathrm{pH}$, salt concentration, and five commonly used additives for preventing aggregation were 
defined as variables. The selection and the level values of five additives were set according to empirical data and literatures [12-14]. And, a 70\% DBC, equal to 12.5 $\mathrm{mg} / \mathrm{mL}$, was adopted as loading quantities, and $\mathrm{pH} 3.25$ was set as $\mathrm{pH}$ center point. The settings and values of responses were all shown in Table 1. According to the result of normal plot analysis, $\mathrm{pH}$, dextran and trehalose were identified as main affects for aggregates $(\mathrm{p}<0.05)$ (see Fig.2a). Meanwhile, $\mathrm{pH}$ was identified as main effect for recovery $(\mathrm{p}<0.05)$. And, interactive effects mainly between $\mathrm{pH}$ and trehalose on both responses were also observed. Based on the significances of their effects on the aggregation, $\mathrm{pH}$ and trehalose were selected as variables for further optimization by using CCC analysis to obtain the optimal elution conditions for higher recovery and lower aggregates. The settings of the CCC were shown in Table 2. Fig. 3 showed the recovery and aggregates as a function of $\mathrm{pH}$ and trehalose concentration. The recovery was $\mathrm{pH}$ dependent and the optimal space was found at low $\mathrm{pH}$. The low ratio of aggregates was achieved at high concentration of trehalose. An interactive effect was revealed between $\mathrm{pH}$ and trehalose. To fulfill both criteria of recovery (above 95\%) and aggregates ratio (below 10\%), it was decided to perform the elution at the $\mathrm{pH}$ range from 2.9 to3.0 with $32 \%-35 \%(\mathrm{w} / \mathrm{v})$ trehalose added. 
Table 1 2-level fractional factorial design for screening of variables during elution and responses

\begin{tabular}{|c|c|c|c|c|c|c|c|c|c|}
\hline \multirow[b]{2}{*}{$\begin{array}{l}\text { Run } \\
\text { order }\end{array}$} & \multicolumn{7}{|c|}{ Variables } & \multicolumn{2}{|c|}{ Responses } \\
\hline & $\begin{array}{l}\text { A: } \\
\text { pH }\end{array}$ & $\begin{array}{l}\text { B: } \\
\mathrm{NaCl} \\
(\mathrm{mM})\end{array}$ & $\begin{array}{l}\text { C: } \\
\text { Urea } \\
(M)\end{array}$ & $\begin{array}{l}\text { D: } \\
\text { Arginine } \\
\text { (M) }\end{array}$ & $\begin{array}{l}\mathbf{E}: \\
\text { Trehalose } \\
(\% \mathrm{w} / \mathrm{v})\end{array}$ & $\begin{array}{l}\text { F: } \\
\text { PEG } \\
(\% \mathrm{w} / \mathrm{v})\end{array}$ & $\begin{array}{l}\text { G: } \\
\text { Dextran } \\
(\% \mathrm{w} / \mathrm{v})\end{array}$ & $\begin{array}{l}\text { Aggregates } \\
(\%)\end{array}$ & $\begin{array}{l}\text { Recovery } \\
(\%)\end{array}$ \\
\hline 1 & $3.25(0)$ & $150(0)$ & $0.55(0)$ & $0.3(0)$ & $17.5(0)$ & $5.5(0)$ & $5.5(0)$ & 18.5 & 93.0 \\
\hline 2 & $3.0(-1)$ & $250(+1)$ & $1.0(+1)$ & $0.5(+1)$ & $5.0(-1)$ & $10(+1)$ & $1.0(-1)$ & 36.4 & 96.1 \\
\hline 3 & $3.5(+1)$ & $250(+1)$ & $1.0(+1)$ & $0.5(+1)$ & $30(+1)$ & $10(+1)$ & $10(+1)$ & 8.8 & 91.3 \\
\hline 4 & $3.0(-1)$ & $50(-1)$ & $0.1(-1)$ & $0.1(-1)$ & $5.0(-1)$ & $1.0(-1)$ & $1.0(-1)$ & 35.2 & 97.0 \\
\hline 5 & $3.5(+1)$ & $250(+1)$ & $0.1(-1)$ & $0.5(+1)$ & $5.0(-1)$ & $1.0(-1)$ & $1.0(-1)$ & 21.1 & 89.5 \\
\hline 6 & $3.5(+1)$ & $50(-1)$ & $0.1(-1)$ & $0.1(-1)$ & $30(+1)$ & $1.0(-1)$ & $10(+1)$ & 8.3 & 92.0 \\
\hline 7 & $3.0(-1)$ & $250(+1)$ & $0.1(-1)$ & $0.5(+1)$ & $30(+1)$ & $1.0(-1)$ & $10(+1)$ & 12.5 & 95.2 \\
\hline 8 & $3.5(+1)$ & $50(-1)$ & $0.1(-1)$ & $0.5(+1)$ & $30(+1)$ & $10(+1)$ & $1.0(-1)$ & 9.4 & 90.0 \\
\hline 9 & $3.0(-1)$ & $250(+1)$ & $0.1(-1)$ & $0.1(-1)$ & $30(+1)$ & $10(+1)$ & $1.0(-1)$ & 13.0 & 96.0 \\
\hline 10 & $3.25(0)$ & $150(0)$ & $0.55(0)$ & $0.3(0)$ & $17.5(0)$ & $5.5(0)$ & $5.5(0)$ & 19.2 & 93.5 \\
\hline 11 & $3.0(-1)$ & $250(+1)$ & $1.0(+1)$ & $0.1(-1)$ & $5.0(-1)$ & $1.0(-1)$ & $10(+1)$ & 35.0 & 97.0 \\
\hline 12 & $3.5(+1)$ & $250(+1)$ & $1.0(+1)$ & $0.1(-1)$ & $30(+1)$ & $1.0(-1)$ & $1.0(-1)$ & 9.3 & 89.7 \\
\hline 13 & $3.0(-1)$ & $50(-1)$ & $1.0(+1)$ & $0.1(-1)$ & $30(+1)$ & $10(+1)$ & $10(+1)$ & 12.5 & 95.4 \\
\hline 14 & $3.0(-1)$ & $50(-1)$ & $0.1(-1)$ & $0.5(+1)$ & $5.0(-1)$ & $10(+1)$ & $10(+1)$ & 35.4 & 95.0 \\
\hline 15 & $3.0(-1)$ & $50(-1)$ & $1.0(+1)$ & $0.5(+1)$ & $30(+1)$ & $1.0(-1)$ & $1.0(-1)$ & 13.3 & 96.0 \\
\hline 16 & $3.25(0)$ & $150(0)$ & $0.55(0)$ & $0.3(0)$ & $17.5(0)$ & $5.5(0)$ & $5.5(0)$ & 18.9 & 92.5 \\
\hline 17 & $3.5(+1)$ & $50(-1)$ & $1.0(+1)$ & $0.1(-1)$ & $5.0(-1)$ & $10(+1)$ & $1.0(-1)$ & 20.0 & 88.9 \\
\hline 18 & $3.5(+1)$ & $250(+1)$ & $0.1(-1)$ & $0.1(-1)$ & $5.0(-1)$ & $10(+1)$ & $10(+1)$ & 19.0 & 89.0 \\
\hline 19 & $3.5(+1)$ & $50(-1)$ & $1.0(+1)$ & $0.5(+1)$ & $5.0(-1)$ & $1.0(-1)$ & $10(+1)$ & 18.6 & 91.0 \\
\hline
\end{tabular}

Number $+1,-1$, and 0 in the bracket indicated the high level, low level, and center point of the variables, respectively.

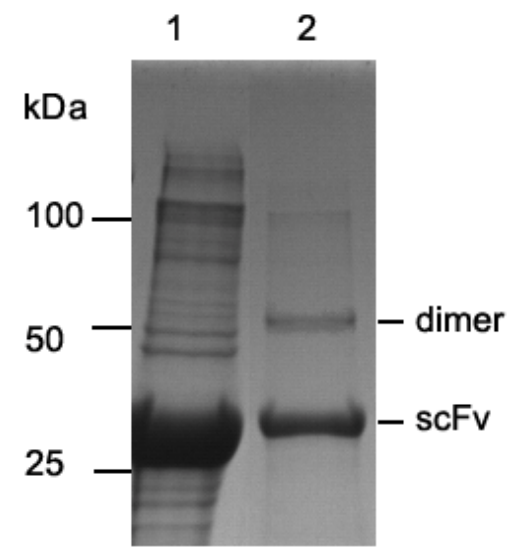

Fig.1 Non-reducing SDS-PAGE analysis of the cell lysates (lane 1) and fraction eluted from Capto L (lane 2). 
(a) Normal plot (Response is aggregates, Alpha $=0.05$ )

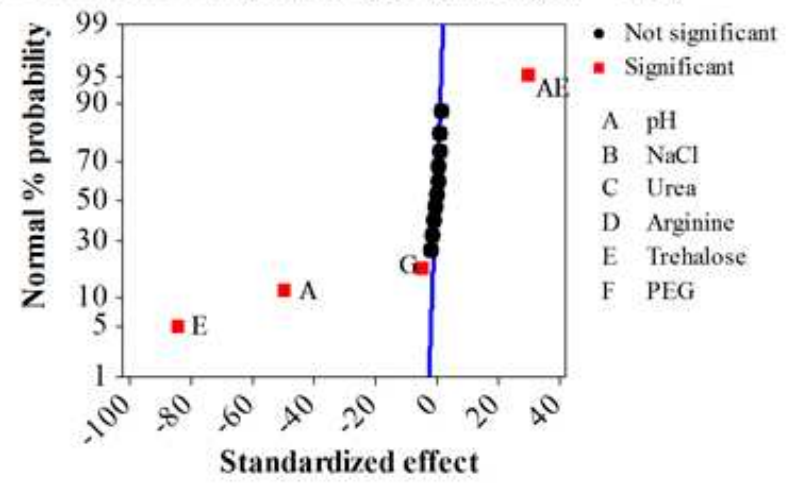

(b) Normal plot (Response is Recovery, Alpha $=0.05$ )

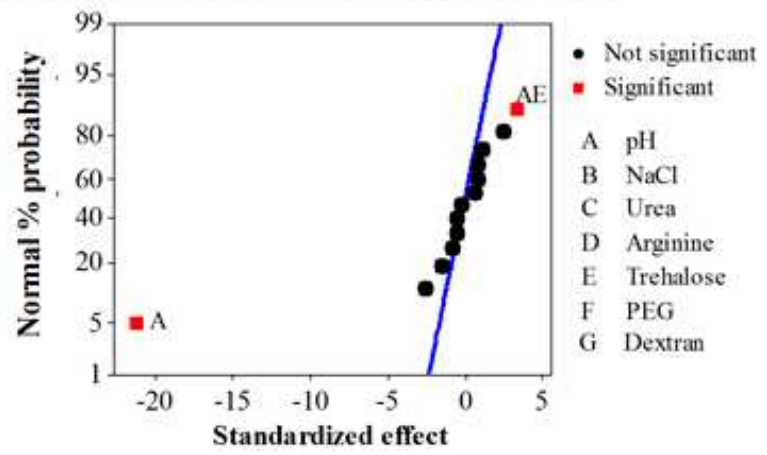

Fig. 2 Normal probability plot for the effects of $\mathrm{pH}, \mathrm{NaCl}$ concentration and additives of the elution buffer on aggregates (a) and recovery (b) of the scFv during purification using Capto L chromatography. The main effects identified were indicated by red rectangle. 
Table 2 CCC design and responses in first capture step

\begin{tabular}{|c|c|c|c|c|}
\hline \multirow{3}{*}{$\begin{array}{l}\text { Run } \\
\text { order }\end{array}$} & & \multirow{3}{*}{$\begin{array}{l}\text { Variables } \\
\text { B: } \\
\text { Trehalose }\end{array}$} & \multicolumn{2}{|c|}{ Responses } \\
\hline & \multirow{2}{*}{$\begin{array}{l}\text { A: } \\
\text { pH }\end{array}$} & & Aggregates & \multirow[t]{2}{*}{ Recovery } \\
\hline & & & $(\%)$ & \\
\hline 1 & 0 & 0 & 17.2 & 92.0 \\
\hline 2 & 1 & -1 & 19.0 & 88.0 \\
\hline 3 & -1 & -1 & 34.0 & 96.0 \\
\hline 4 & 0 & 0 & 17.0 & 92.5 \\
\hline 5 & 0 & -1.414 & 35.0 & 92.0 \\
\hline 6 & -1.414 & 0 & 20.0 & 98.0 \\
\hline 7 & 1 & 1 & 8.2 & 90.0 \\
\hline 8 & 1.414 & 0 & 14.0 & 85.0 \\
\hline 9 & 0 & 0 & 17.9 & 92.3 \\
\hline 10 & 0 & -1.414 & 7.6 & 93.0 \\
\hline 11 & 0 & 0 & 17.5 & 92.8 \\
\hline 12 & 0 & 0 & 17.8 & 92.5 \\
\hline 13 & -1 & 1 & 13.0 & 96.0 \\
\hline
\end{tabular}

Note: Number 1.414, $-1.414,1,-1$, and 0 represented $\mathrm{pH} 3.6,2.9,3.5,3.0$, and 3.25, and trehalose concentration of $35 \%, 0,30 \%, 5 \%$, and $17.5 \%(\mathrm{w} / \mathrm{v})$, respectively.
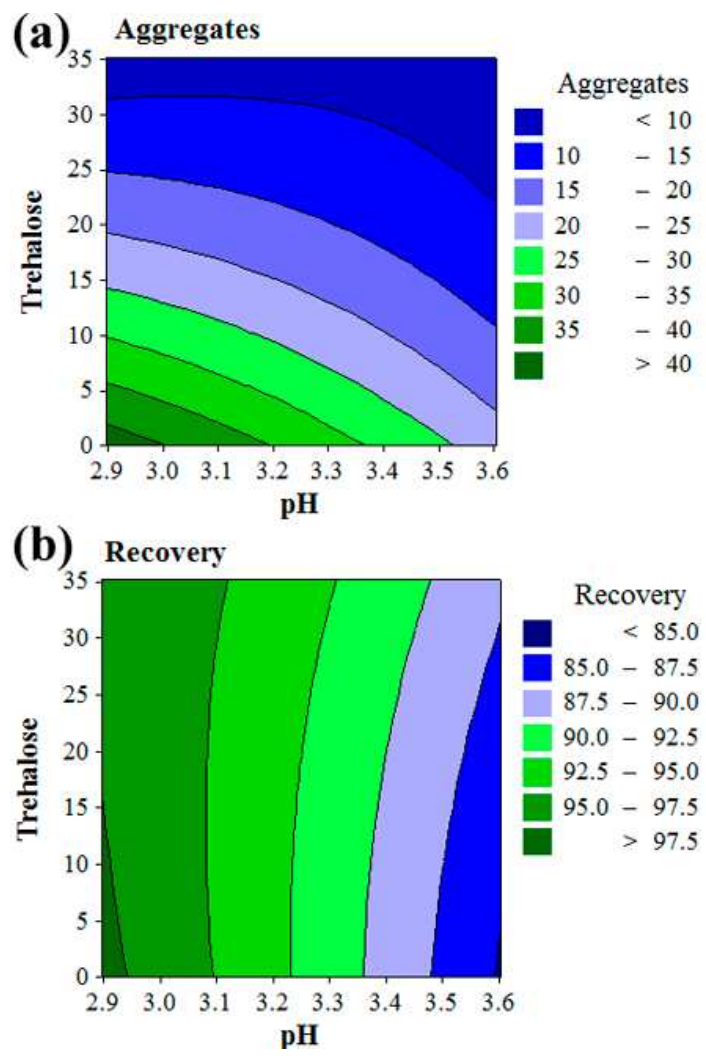
Fig. 3 Contour plots for aggregates (a) and recovery (b) using Capto L. The ranges of the two responses represented by different colors were indicated on right. (color figure can be seen in the online version of this article).

\section{Optimization of the cation exchange chromatography step}

In the second purification step, the remaining dimer was the major impurity need to be separated. Considering the basic pI (8.7) of the target scFv, two cation exchange media, Capto S and SP Sepharose ${ }^{\circledR}$ Fast Flow, were initially chosen for the purification. The selectivity and recovery of each medium were tested at $\mathrm{pH} 5.0,6.0$ and 7.0, using a $\mathrm{NaCl}$ linear gradient elution from 0 to $1.0 \mathrm{M}$. Capto $\mathrm{S}$ presented better selectivity at $\mathrm{pH} 6.0$ (data not shown), although there was little difference in recovery between all tested conditions, thus this medium was selected for further optimization. Next, a CCC design based on two variables (pH and loading conductivity) was set up to determine the salt concentration and the $\mathrm{pH}$ needed to obtain high DBC and purity. Accordingly, the DBC of the target protein as well as the purity of eluted product were set as responses. See Table 3 for setting details. Fig. 4a showed the contour plot for DBC. As expected, lower $\mathrm{pH}$ generated higher DBC, and this trend was slightly offset as the conductivity increased. Fig. $4 \mathrm{~b}$ showed the contour plot for purity, the highest purity was found near $\mathrm{pH} 6.0$, while the loading conductivity played a minor effect on this response. Based on these results, $\mathrm{pH}$ 5.9-6.1 and loading conductivity 5-12.5 mS/cm were considered as optimal conditions for this step. 
Table 3 CCC design and responses in the second step

\begin{tabular}{|c|c|c|c|c|}
\hline \multirow[b]{2}{*}{$\begin{array}{l}\text { Run } \\
\text { order }\end{array}$} & \multirow{2}{*}{\multicolumn{2}{|c|}{$\begin{array}{l}\text { Variables } \\
\text { B: } \\
\text { Conductivity }\end{array}$}} & \multicolumn{2}{|c|}{ Responses } \\
\hline & & & $\begin{array}{l}\text { DBC } \\
(\%) \\
\end{array}$ & $\begin{array}{l}\text { Purity } \\
(\%)\end{array}$ \\
\hline 1 & 0 & 0 & 130 & 93 \\
\hline 2 & 1 & -1 & 87 & 96 \\
\hline 3 & -1 & -1 & 68 & 94 \\
\hline 4 & 0 & 0 & 118 & 94 \\
\hline 5 & 0 & -1.414 & 88 & 96 \\
\hline 6 & -1.414 & 0 & 40 & 94 \\
\hline 7 & 1 & 1 & 90 & 97 \\
\hline 8 & 1.414 & 0 & 91 & 96 \\
\hline 9 & 0 & 0 & 88 & 97 \\
\hline 10 & 0 & 1.414 & 70 & 95 \\
\hline 11 & 0 & 0 & 99 & 97 \\
\hline 12 & 0 & 0 & 133 & 94 \\
\hline 13 & -1 & 1 & 39 & 93 \\
\hline
\end{tabular}

Note: Number 1.414, $-1.414,1,-1$, and 0 represented $\mathrm{pH} 7.4,4.59,7.0,5.0$, and 6.0, and conductivity of $17.1,2.9,15,5$, and $10 \mathrm{mS} / \mathrm{cm}$, respectively.
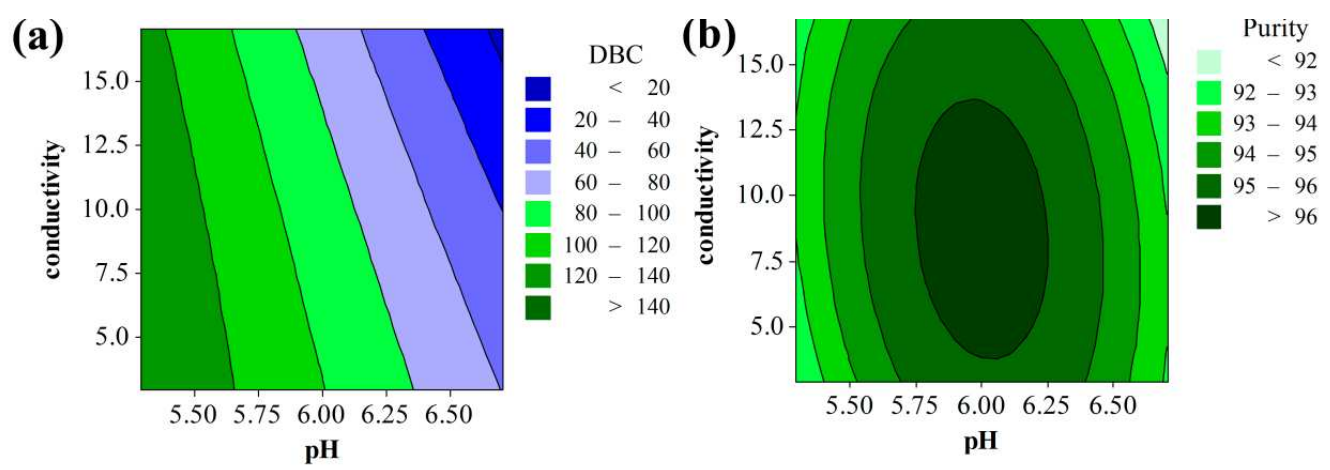

Fig.4 Contour plots for DBC (a) and purity (b) using Capto S. $\mathrm{R}^{2}=0.99$. (color figure can be seen in the online version of this article)

\section{Gel filtration and purity determination of final product}

In final step of purification, the Superdex 75 medium was used to remove the trace aggregates and to desalt. The final products were stored in PBS. A following 
HPLC detection was performed to determine the purity of the target protein. Accordingly, the final sample was $98 \%$ in purity (see Fig. 5). And the recovery was calculated as $94 \%$ in this step.

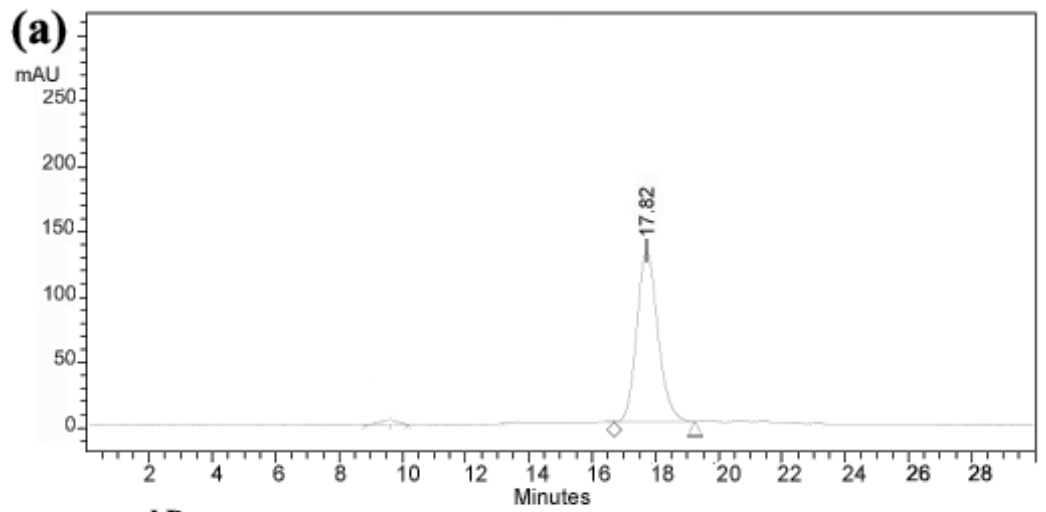

(b)

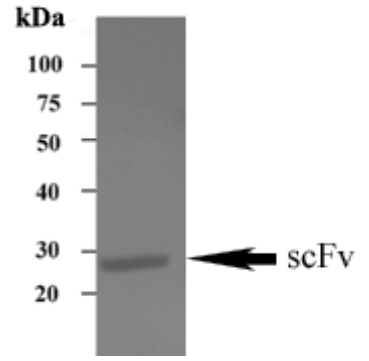

Fig. 5 Purity analysis of the purified scFv by using SEC-HPLC (a) and non-reducing SDS-PAGE (b).

\section{Verification of the optimal purification conditions}

Having optimized the three purification steps and having gained the optimal space for each step, a 20-fold scale-up process verification was performed. Accordingly, 88 grams wet cells (with $250 \mathrm{mg}$ target protein included) from eight liters cultures were used as starting sample. Purity and recovery of the target fraction in each purification step were calculated. The results were summarized in Table 4. All values fell within the predicted regions that were determined in small scale DoE design, implying the robustness of the optimal conditions. The total yield of final 
product was $77 \%$ (equal to $1.9 \mathrm{mg}$ purified $\mathrm{scFv}$ per $\mathrm{g}$ of wet weight cells), and the purity was up to $98.5 \%$ according to SEC-HPLC analysis.

Table 4 Summary of the verification experiment result

\begin{tabular}{ccc}
\hline Fraction & Purity & \% Yield \\
\hline Lysate & ND & 100 \\
Capto L & $86.4 \%\left(93 \%^{*}\right)$ & $89\left(95.6^{*}\right)$ \\
Capto S & $96 \%$ & 82 \\
Superdex 75 & $98.5 \%$ & 77 \\
\hline ND, not determined. & \\
*if dimer aggregates were included.
\end{tabular}

\section{Discussion}

Design of experiments (DoE) is a structured and organized statistical method for planning experiments and analyzing the information obtained. Based on the information obtained, a mathematical model can be built to help understand the relationships between variables and responses, and help identify the main effects and predict their optimal space for certain objective. In this study, DoE was applied into purification optimization of a recombinant $\mathrm{scFv}$ against IGF-IR that is a promising target for a wide range of cancers, whereby the optimal purification conditions were efficiently established and the final product was obtained with high purity and yield. This laid a foundation for the bioprocess of the $\mathrm{scFv}$ in a further diagnostic or therapeutic application.

Affinity chromatography based on protein A or protein L has been commonly used for purifying antibodies or antibody fragments because of its high specificity. However, the acidic $\mathrm{pH}$ elution used in this method often leads to undesired aggregation or even precipitation of target proteins, which was the case here. 
Generally, in this case, a wide range of additives such as amino acids, disaccharides, polyhydroxy alcohols, non-ionic detergents could be used to ameliorate the aggregation [12-14]. As the effects of these additives are case-by-case, there is no generic formulation available. Thus a wide screening for identifying the best ones or proper combinations needs to be performed, but this would be a tough task if using the traditional OFAT method for the screening. The fractional factorial analysis approach used here allowed analyzing many factors simultaneously and identifying the main effects rapidly, thus largely reducing the experiment number and saving time and labors. The CCC design employed then helped focus on the optimal conditions In this study, trehalose was identified as the most effective additive for preventing aggregation of the target $\mathrm{scFv}$ upon acidic $\mathrm{pH}$ elution, while other additives showed minor effects. This again indicated that the effects of the additives are hard to be predicted, and the choice of the additives should be assessed on a case-by-case basis. Anyway, the DoE approach used in this step could be referenced when the aggregation issue happens in the protein A or protein L affinity chromatography of other antibodies or antibody fragments.

In conclusion, a three-step purification process for a $\mathrm{scFv}$ against human IGF-IR was optimized in a small scale using DoE approach, and then verified in a 20-fold scale-up experiment. The total yield reached $77 \%$, and the purity of the final product was up to $98.5 \%$. We proposed that the DoE design described in this study has wide applicability in the production of other recombinant scFvs with kappa light chain. 


\section{Acknowledgements}

We thank Dr. Feng Zhang for his valuable and helpful suggestions on protein expression and DoE design.

\section{Author's contribution}

Yong-Hong Song and Xue-Wen Sun performed the experiments and wrote the manuscript. Xian-Hui Su designed and supervised the study. Bo Jiang assisted in performing the protein purification. Ji-En Liu provided consultation.

\section{Conflict of Interest}

The authors declare that they have no conflict of interest.

\section{References}

1. R.C. Baxter, Insulin-like growth factor (IGF)-binding proteins: interactions with IGFs and intrinsic bioactivities, Am. J. Physiol. Endocrinol. Metab. 278(2000) E967-E976.

2. M. Pollak, Insulin and insulin-like growth factor signalling in neoplasia, Nat. Rev. Cancer 8(2008) 915-928.

3. E.J. Gallagher, D. LeRoith, The proliferating role of insulin and insulin-like growth factors in cancer, Trends Endocrinol. Metab. 21(2010) 610-618.

4. A. Arcaro, Targeting the insulin-like growth factor-1 receptor in human cancer, Front. Pharmacol. 4(2013) 30.

5. Z.A. Ahmad, S.K. Yeap, A.M. Ali, W.Y. Ho, N.B. Alitheen, M. Hamid, scFv 
antibody: principles and clinical application, Clin. Dev. Immunol. 2012(2012) 980250.

6. N.E. Weisser, J.C. Hall, Applications of single-chain variable fragment antibodies in therapeutics and diagnostics, Biotechnol. Adv. 27(2009) 502-520.

7. X.W. Sun, X.H. Wang, Y.B. Yao, Co-expression of Dsb proteins enables soluble expression of a single-chain variable fragment $(\mathrm{scFv})$ against human type 1 insulin-like growth factor receptor (IGF-1R) in E. coli, World J. Microbiol. Biotechnol. 30(2014) 3221-3227.

8. I. Amadeo, L. Mauro, E. Ortí, G. Forno, Establishment of a design space for biopharmaceutical purification processes using DoE, Methods Mol. Biol. 1129(2014) 11-27.

9. C. Jiang, L. Flansburg, S. Ghose, P. Jorjorian, A.A. Shukla, Defining process design space for a hydrophobic interaction chromatography (HIC) purification step: application of quality by design (QbD) principles, Biotechnol. Bioeng. 107(2010) 985-97.

10. E. Heldin, S. Grönlund, J. Shanagar, E. Hallgren, K. Eriksson, M. Xavier, H. Tunes, L. Vilela, Development of an intermediate chromatography step in an insulin purification process. The use of a High Throughput Process Development approach based on selectivity parameters, J. Chromatogr. B 973(2014) 126-132.

11. A. Gualberto, Figitumumab (CP-751,871) for cancer therapy, Expert Opin. Biol.Ther.10(2010) 575-585.

12. W.Wang, Protein aggregation and its inhibition in biopharmaceutics, Int. J.Pharm. 
289(2005) 1-30.

13. S.E. Bondos, A. Bicknell, Detection and prevention of protein aggregation before, during, and after purification, Anal. Biochem. 316(2003) 223-231.

14. T.J. Kamerzell, R. Esfandiary, S.B. Joshi, C.R. Middaugh, D.B. Volkin, Protein-excipient interactions: mechanisms and biophysical characterization applied to protein formulation development, Adv. Drug Deliv. Rev. 63(2011) 1118-1159. 